
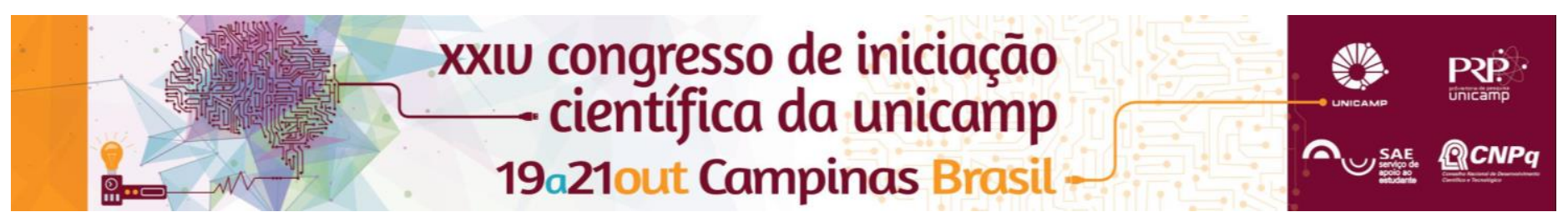

\title{
Adição de cal hidratada e resíduo de isolador de porcelana em argamassas álcali-ativadas
}

\author{
Conrado G. Saldeira*, Rodrigo H. Geraldo, Gladis Camarini.
}

\section{Resumo}

O objetivo deste trabalho é analisar a influência da adição de cal hidratada e a substituição de uma parte da areia por resíduo de isolador elétrico de porcelana (RIP) em argamassas álcali-ativadas. Verificaram-se alterações de resistência mecânica à compressão e à tração na flexão, sendo que foi observado aumento da resistência aos 28 dias com a utilização da cal e do RIP, atingindo 9,7 MPa para flexão e 33,1 MPa para compressão com $5 \%$ de cal e $70 \%$ de substituição de resíduo. Os resultados revelam um grande potencial para a produção de componentes para a construção civil.

\section{Palavras-chave}

Geopolímeros, propriedades mecânicas, cal hidratada.

\section{Introdução}

Os materiais álcali-ativados (ou geopolímeros) representam uma alternativa ao cimento Portland comum $^{1}$ e mostram-se como um aglomerante promissor. Este trabalho visa o estudo de geopolímeros, resultado de uma ativação alcalina de aluminossilicatos (materiais ricos em alumínio e silicato) em uma reação complexa de polimerização. Eles apresentam uma solução menos poluente e ainda possibilitam a incorporação de resíduos, tornando-se muito importante atualmente. $\mathrm{O}$ objetivo desta pesquisa é estudar esses materiais e verificar a influência da adição de cal ${ }^{2}$ e a substituição da areia por resíduo de isolador elétrico nas propriedades mecânicas de argamassas geopoliméricas.

\section{Materiais e Métodos}

Os materiais utilizados foram o $\mathrm{NaOH}$, a cinza de casca de arroz (CCA), o metacaulim (MK), água, areia e RIP.

Para o preparo adiciona-se água, $\mathrm{NaOH}$ e CCA e essa mistura entra em agitação e aquecimento $\left(90^{\circ} \mathrm{C} \pm 5^{\circ} \mathrm{C}\right)$ por 30 minutos para dissolver a sílica. Na mistura adiciona-se MK e areia para cura em temperatura ambiente. Foram utilizados $1 \%$ e $5 \%$ de cal em massa total (sem areia) e RIP, 70\% em massa de areia.

Foram avaliadas as resistências à compressão e à tração por flexão.

\section{Resultados e Discussão}

Nota-se um aumento da resistência tanto na flexão quanto na compressão adicionando-se cal, sendo que porcentagens menores de $1 \%$ praticamente não alteram as propriedades. No entanto, adições superiores (5\%) já são suficientes para aumentar em $18 \%$ a resistência à compressão e $15 \%$ à flexão (Tabela1).

Tabela 1. Resistência à flexão e à compressão de argamassas com diferentes teores de cal (MPa).

\begin{tabular}{|c|c|c|c|}
\hline $\begin{array}{c}\text { Propriedades } \\
\text { Mecânicas }\end{array}$ & R+lsolador & $\begin{array}{c}\text { R+lsolador+ } \\
1 \% \text { cal }\end{array}$ & $\begin{array}{c}\text { R+lsolado } \\
\mathrm{r}+5 \% \text { cal }\end{array}$ \\
\hline $\begin{array}{c}\text { Compressão } \\
\text { (MPa) }\end{array}$ & 28 & 26,9 & 33,1 \\
\hline Flexão (MPa) & 8,4 & 9,2 & 9,7 \\
\hline
\end{tabular}

$\mathrm{O}$ isolador de porcelana, por ter maior finura, diminui a formação de poros e aumenta a resistência (Tabela 2), atingindo um aumento de $27 \%$ para tração e $33 \%$ para compressão.

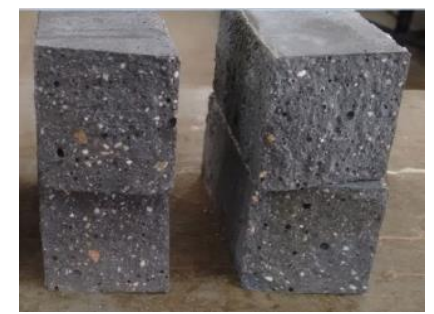

Figura 1. Corpo de Prova de geopolímero

Tabela 2. Resistência à flexão e à compressão de argamassas com e sem resíduo de isolador (MPa).

\begin{tabular}{|c|c|c|}
\hline $\begin{array}{c}\text { Propriedades } \\
\text { Mecânicas }\end{array}$ & $\mathrm{R}+5 \%$ cal & $\begin{array}{c}\text { R+Porcelana+5\% } \\
\text { cal }\end{array}$ \\
\hline Compressão (MPa) & 24,8 & 33,1 \\
\hline Flexão (MPa) & 7,6 & 9,7 \\
\hline
\end{tabular}

\section{Conclusões}

A utilização de cal hidratada em argamassas álcaliativadas se mostrou benéfica, aumentando a resistência mecânica do aglomerante proposto. Os resultados mostram também que pequenas proporções de cal não apresentam o efeito esperado, e à medida que aumentamos a adição aumenta-se a sua influência aos 28 dias de cura. Em relação ao resíduo de isolador elétrico o estudo apresentou bons resultados, obtendo em torno de $30 \%$ de aumento nas resistências aos 28 dias. Além disso, por ser um material fino, tem uma tendência de diminuir a porosidade do material final.

\section{Agradecimentos}

Os autores agradecem ao CNPq e CAPES pelo apoio financeiro e ao LARES pelo suporte técnico.

[1] B. Majidi, Materials Technology 24, 79-87 (2009).

[2] J. Temuujin, R.P.Williams, A. van Riessen, J. of Mat. Proc. Tech. 209, 5276-5280 (2009). 